Manuscript accepted for publication in the Journal Materials and Structures

\title{
MECHANICAL BEHAVIOUR OF HYPERCOMPACTED EARTH FOR BUILDING CONSTRUCTION
}

\author{
Agostino Walter Bruno ${ }^{1}$, Domenico Gallipoli ${ }^{1}$, Céline Perlot $^{1}$, Joao Mendes ${ }^{2}$ \\ ${ }^{1}$ Laboratoire SIAME, Université de Pau et des Pays de l'Adour, 64600 Anglet, France. \\ ${ }^{2}$ School of Engineering and Computing Science, University of Durham, United Kingdom.
}

DATE OF SUBMISSION: 15/03/2017

NUMBER OF WORDS: 4776

NUMBER OF TABLES: 3

NUMBER OF FIGURES: 12

CORRESPONDING AUTHOR: Agostino Walter BRUNO

Université de Pau et des Pays de l'Adour

Laboratoire SIAME - Bâtiment ISABTP

Allée du Parc Montaury

64600 Anglet

France

e-mail: agostinowalter.bruno@univ-pau.fr 


\section{ABSTRACT}

This paper investigates the mechanical behaviour of a hypercompacted unstabilized earth material manufactured by compressing a moist soil to very high pressures up to $100 \mathrm{MPa}$. The hypercompaction procedure increases material density, which in turn improves mechanical characteristics. Samples were manufactured at the scale of both small cylinders and masonry bricks. The effect of ambient humidity on the mechanical characteristics of the material was investigated at the scale of cylindrical samples, showing that both strength and stiffness are sensitive to environmental conditions and tend to increase as ambient humidity reduces. The strength of the bricks was instead investigated under laboratory ambient conditions by using different experimental configurations to assess the influence of sample slenderness and friction confinement. Additional tests were also performed to evaluate the influence of mortar joints and compaction-induced anisotropy. Overall, the hypercompacted earth material exhibits mechanical characteristics that are comparable with those of traditional building materials, such as fired bricks, concrete blocks or stabilized compressed earth.

\section{KEYWORDS}

Raw earth, hypercompaction, compacted earth bricks, Young modulus, compressive strength, rammed earth, earth construction, bio-sourced construction materials. 


\section{INTRODUCTION}

The use of raw earth as a construction material can significantly reduce the environmental impact of current building practice. Raw earth can be locally sourced (Morel et al., 2001) and, when used without chemical stabilisers, can be entirely recycled upon demolition. Raw earth also possesses advantageous hygroscopic characteristics as it "breathes" by adsorbing or releasing moisture depending on ambient humidity. This helps to regulate the hygrothermal conditions of indoor environments and significantly improves the comfort of occupants in the absence of artificial airconditioning (Allinson and Hall, 2010; Pacheco-Torgal and Jalali, 2012; McGregor et al., 2014).

Despite all the above benefits, raw earth remains a niche building material because of its perceived mechanical weakness and the absence of standard procedures to measure strength and stiffness (Aubert et al., 2016). In addition, the effect of ambient humidity on the mechanical characteristics of raw earth materials requires further investigation (e.g. Dierks and Ziegert, 2002; Beckett and Augarde, 2012; Bui et al., 2014; Champiré et al., 2016).

Previous research has shown that the application of a larger compaction effort during fabrication significantly increases the strength and stiffness of earthen materials (Olivier and Mesbah, 1986; Venkatarama Reddy and Jagadish, 1993; Attom, 1997; Mesbah et al., 1999; Kouakou and Morel, 2009), though the compaction levels adopted in previous studies has been relatively low.

This paper presents an innovative manufacturing procedure which significantly improves the mechanical characteristics of raw earth by applying a high compaction pressure up to $100 \mathrm{MPa}$. This procedure, referred to as "hypercompaction", has been employed to fabricate small cylindrical samples and masonry bricks.

The influence of ambient humidity on the stiffness and strength of the material has been explored by testing cylindrical samples equalised under different climatic conditions. Instead, the dependency of strength on experimental variables, such as sample slenderness and friction 
confinement, has been assessed by testing bricks equalised under laboratory conditions. Additional tests have been performed on cubic specimens loaded along different directions to explore the effect of compaction-induced anisotropy as well as on superposed half-bricks to evaluate the effect of a mortar joint on compressive strength.

The results from the above testing campaign have indicated that hypercompacted earth exhibits excellent mechanical properties, which are comparable to those of standard building materials such as masonry bricks, concrete blocks and stabilised earth.

\section{MATERIAL AND METHODS}

\section{$\underline{\text { Material }}$}

The soil used in the present work has been provided by a brickwork factory from the region of Toulouse (France). The grain size distribution has been determined by wet sieving and sedimentation according to the norms XP P94-041 (AFNOR, 1995) and NF P 94-057 (AFNOR, 1992), respectively. The plasticity properties of the fine fraction (i.e. the fraction passing through the $400 \mu \mathrm{m}$ sieve) have been determined according to the norm NF P94-051 (AFNOR, 1993). As shown by Bruno et al. (2015), both the grain size distribution and the plasticity properties satisfy current recommendations for raw earth construction.

Clay activity, defined as the ratio between the plasticity index and the clay fraction smaller than 2 $\mu \mathrm{m}$, is equal to 0.79 . This classifies the clay as normally active (Skempton, 1953) consistent with the mineralogy data provided by the soil supplier, which indicate a predominantly illitic material with a small quantity of montmorillonite. Illite is a three layers-clay with good bonding characteristics and limited swelling upon wetting, which makes this material particularly suited for raw earth construction (Dierks and Ziegert, 2002). The specific gravity of the soil grains $\mathrm{G}_{\mathrm{s}}$ has 
been measured by means of the pycnometer test according to the norm NF P 94-054 (AFNOR, 1991). Table 1 summarises the main properties of the tested soil.

Table 1. Main material properties

\begin{tabular}{ccc}
\hline \multicolumn{3}{c}{ Grain size distribution } \\
\hline Gravel & $>2 \mathrm{~mm}$ & $0.4 \%$ \\
Sand & $0.063-2 \mathrm{~mm}$ & $40.4 \%$ \\
Silt & $0.002-0.063 \mathrm{~mm}$ & $42.9 \%$ \\
Clay & $<0.002 \mathrm{~mm}$ & $16.3 \%$ \\
\hline \multicolumn{2}{c}{ Plasticity properties } \\
\hline Liquid limit, $\mathrm{W}_{\mathrm{L}}(\%)$ & $33.0 \%$ \\
Plastic limit, $\mathrm{W}_{\mathrm{P}}(\%)$ & $20.1 \%$ \\
Plasticity index, $\mathrm{I}_{\mathrm{p}}(\%)$ & $12.9 \%$ \\
Activity A (-) & 0.79 \\
\hline \multicolumn{2}{c}{ Specific gravity of soil grains } \\
\hline \multicolumn{2}{c}{$\mathrm{G}_{\mathrm{s}}(-)$}
\end{tabular}

\section{Small scale cylindrical samples}

The soil was statically compacted in cylindrical samples of $50 \mathrm{~mm}$ diameter and $100 \mathrm{~mm}$ high at three pressure levels of $25 \mathrm{MPa}, 50 \mathrm{MPa}$ and $100 \mathrm{MPa}$. The lowest pressure level is comparable to that applied by the most powerful presses available on the market for manufacturing compressed earth bricks. The other two pressure levels were instead chosen according to a geometrical progression with a ratio of two.

Prior to compaction, 500 grams of dry soil were mixed with the desired amount of water by using an electrical planetary blender for at least 15 minutes. This mixing time was sufficient to ensure a good distribution of moisture throughout the soil (Kouakou and Morel, 2009). The material was subsequently placed inside two plastic bags to prevent evaporation and was left to equalise for at least one day so that moisture could redistribute. After this, the soil was scooped inside a cylindrical steel mould with an inner diameter of $50 \mathrm{~mm}$ and compressed to the required pressure by using a 
load-controlled Zwick/Roell Amsler HB250 press with a capacity of $250 \mathrm{kN}$. Pressure was applied to the soil by two cylindrical aluminium pistons acting at the top and bottom of the specimen (Figure 1). This double-piston compression reduces the effect of the friction between the mould and the sample, thus increasing stress uniformity inside the soil. A finely perforated aluminium disk and filter papers were placed between the top and bottom surfaces of the specimen and the respective piston. This was considered necessary to facilitate the drainage of pore air/water and to accelerate dissipation of overpressures during consolidation under constant load.

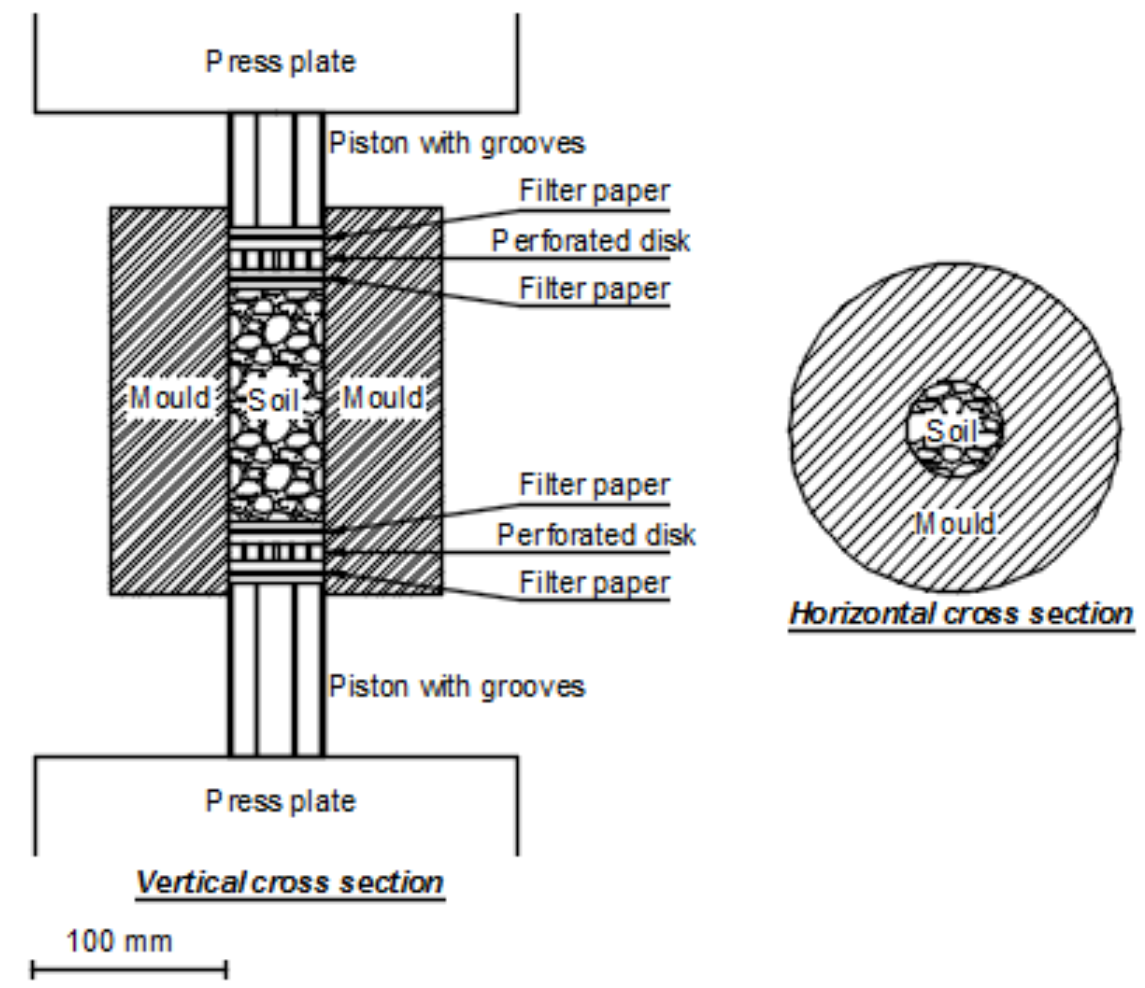

Figure 1. Schematic of compaction set-up for cylindrical samples

The compaction pressure was applied at a relatively fast rate of $5 \mathrm{MPa} / \mathrm{s}$, followed by consolidation under constant load until the vertical displacement rate became less than $0.01 \mu \mathrm{m} / \mathrm{s}$. This rate was measured as the slope of the straight line that fits the final hour of the displacement versus time curve (Figure 2). 
Figure 2 shows the graphic construction suggested by Taylor and Merchant (1940) to determine the time $t_{90}$ to achieve $90 \%$ of primary consolidation. The slope of the secant line intercepting the consolidation curve at $90 \%$ of primary consolidation (thick line in Figure 2) is obtained by dividing the tangent slope at the origin (dotted line in Figure 2) by a factor of 1.15. Inspection of Figure 2 indicates that $90 \%$ of primary consolidation is attained after only few minutes of consolidation. The adopted displacement rate of $0.01 \mu \mathrm{m} / \mathrm{s}$ is therefore less than $0.25 \%$ of the average displacement rate during primary consolidation, which is about $4 \mu \mathrm{m} / \mathrm{s}$ according to the slope of the secant line in Figure 2. The very low displacement rate adopted in this work ensures the occurrence of all primary consolidation and a large portion of secondary consolidation but unfortunately increases significantly fabrication time, which complicates industrial production. The need of such a strict consolidation criterion will be further investigated in the following part of this paper.

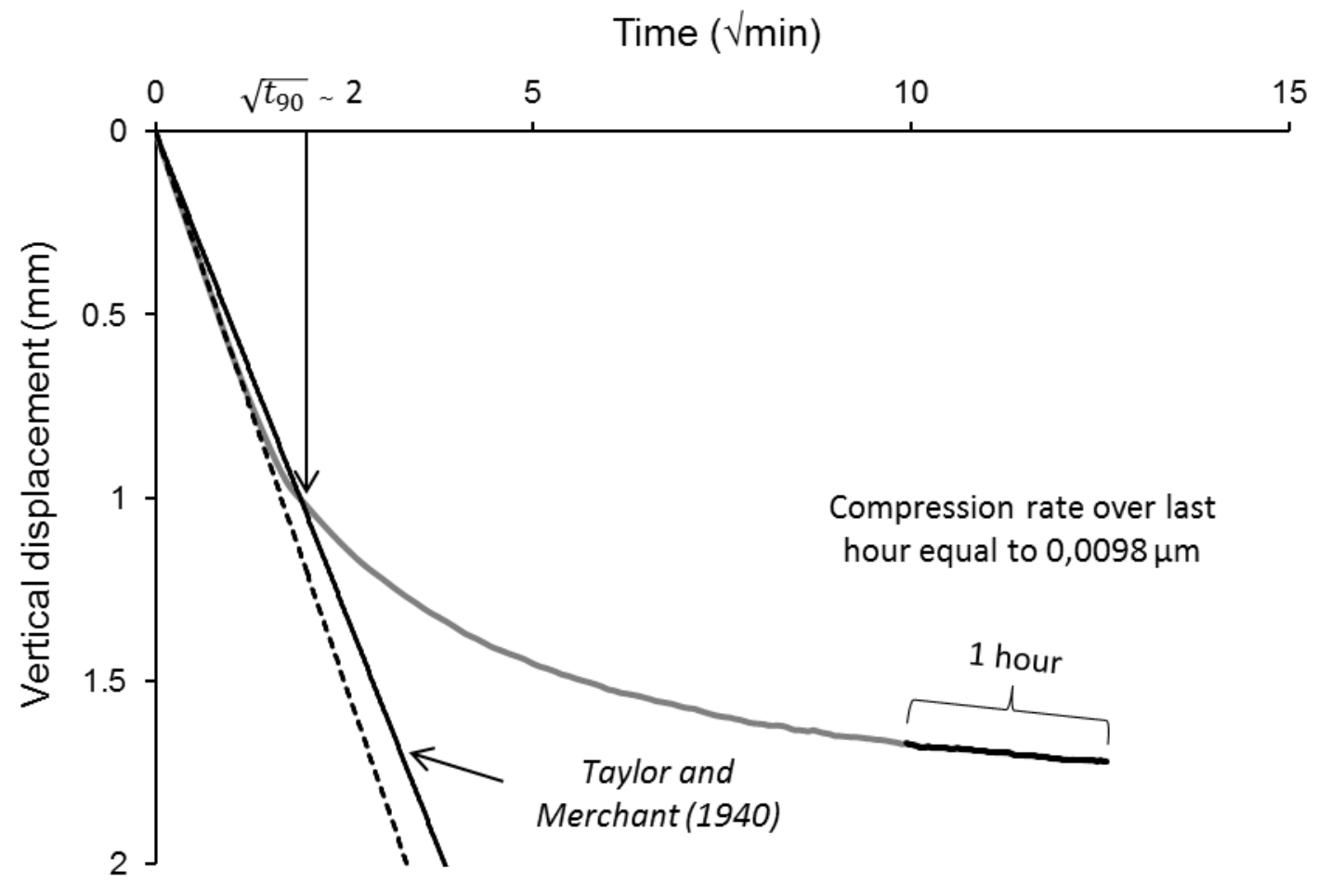

Figure 2. Typical curve of vertical displacement versus square root of time during consolidation 
After consolidation, specimens were demoulded and cut down to a height of $100 \mathrm{~mm}$ by trimming the excess soil from the top and bottom extremities. The water contents of the top and bottom trimmings were then measured giving very similar values, which suggests an uniform distribution of moisture across the sample. The two measurements were also consistent with the amount of water added to the dry soil before compaction, which excluded any inhomogeneity of moisture content along the height of the sample caused by drainage at the two extremities. The water content of the entire specimen was then taken as the average of the two measurements from the top and bottom trimmings.

For comparison, a number of samples were also compacted according to the Proctor standard in compliance with the norm NF P 94-093 (AFNOR, 1999). After compaction, a cylindrical specimen of $50 \mathrm{~mm}$ diameter was cored from the larger Proctor sample. The corresponding water content was determined as the average value from three samples of about 50 grams each, taken from the leftover soil after coring. The cored specimen was then cut down to a height of $100 \mathrm{~mm}$ by trimming the top and bottom extremities.

For all specimens, three measurements of diameter were taken at different heights and three measurements of height were taken at different angles. The volume of the specimen was then calculated from the average values of diameter and height while the mass was recorded by using a scale with a resolution of $0.01 \mathrm{~g}$. Based on the measured values of mass, water content, volume and specific gravity, it was then possible to calculate bulk density, dry density, porosity and degree of saturation.

After compaction, all samples were equalised inside a climatic chamber at a temperature of $25{ }^{\circ} \mathrm{C}$ and a relative humidity of $62 \%$, which represents a typical indoor ambient condition, to measure their change in density and saturation. Equalisation took about 15 days and was considered complete when the specimen mass changed less than $0.1 \%$ over at least one week. 
Figure 3 shows the values of dry density plotted against the corresponding water contents for each compaction level, after compaction (hollow markers) and after equalisation (solid markers). The compaction curves are also shown in Figure 3, which allows the determination of the optimum water content corresponding to the highest dry density for each compaction level.

Inspection of Figure 3 indicates that, as the compaction effort increases from the Proctor standard to $25 \mathrm{MPa}, 50 \mathrm{MPa}$ and $100 \mathrm{MPa}$, the optimum water content reduces while the corresponding dry density increases. The dry density increases less than linearly with compaction pressure, i.e. the increase in dry density from $25 \mathrm{MPa}$ to $50 \mathrm{MPa}$ is greater than the increase in dry density from 50 $\mathrm{MPa}$ to $100 \mathrm{MPa}$. It would therefore be necessary to apply an unfeasibly high compaction pressure to attain the theoretical "no porosity" point where the dry density of the soil becomes equal to the density of particles.

During equalisation, all samples experienced desaturation and shrinkage as the water content reduced to the same value of about $3.5 \%$ and the dry density increased especially for the wettest samples (Figure 3).

During equalisation, raw earth tended to shrink leading to an increase of dry density which depended on the compaction water content. In particular, at the end of equalisation, dry density became almost identical for specimens compacted to the highest pressure of $100 \mathrm{MPa}$ but remained significantly different specimens compacted to lower pressure levels (Figure 3). The dependency of the post-equalisation dry density on compaction water content seems therefore to reduce as compaction effort increases. This in turn suggests that a higher compaction effort may help to standardise material properties and therefore facilitate quality control during fabrication. 


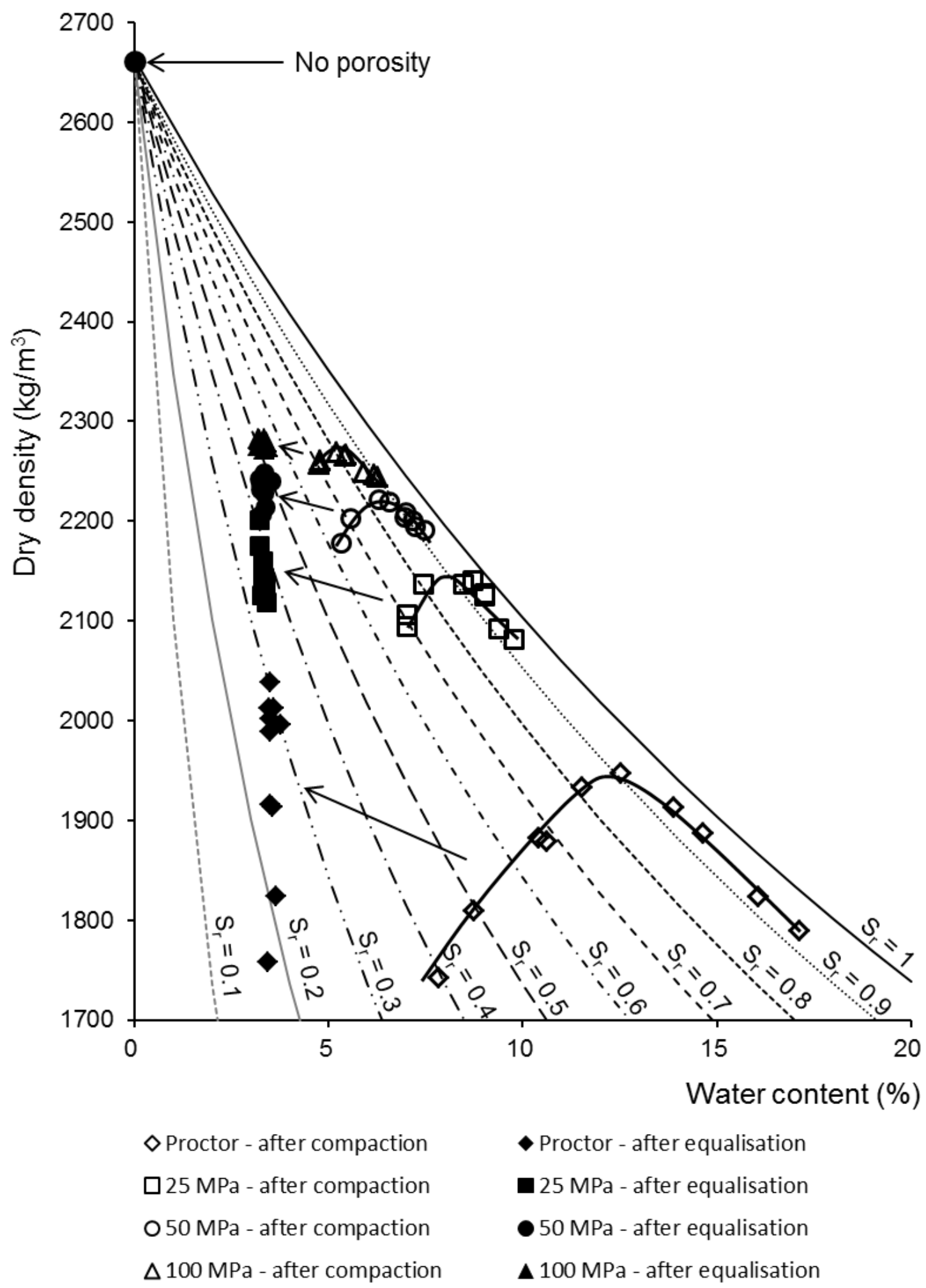

Figure 3. Compaction curves at 25, 50 and $100 \mathrm{MPa}$ together with standard Proctor after compaction (hollow markers) and after equalisation (solid markers) 


\section{Large scale compressed earth bricks}

The hypercompaction method employed for the fabrication of small cylindrical samples was subsequently extended to the production of larger bricks. Earth bricks with dimensions of $200 \times 100$ x $50 \mathrm{~mm}^{3}$ were double-compacted to a pressure of $100 \mathrm{MPa}$ at the optimum water content of $5.2 \%$. The optimum water content was assumed to be the same as that of the cylindrical samples compacted at the same pressure. Figure 4 shows the mould together with the two pistons used to manufacture the bricks.
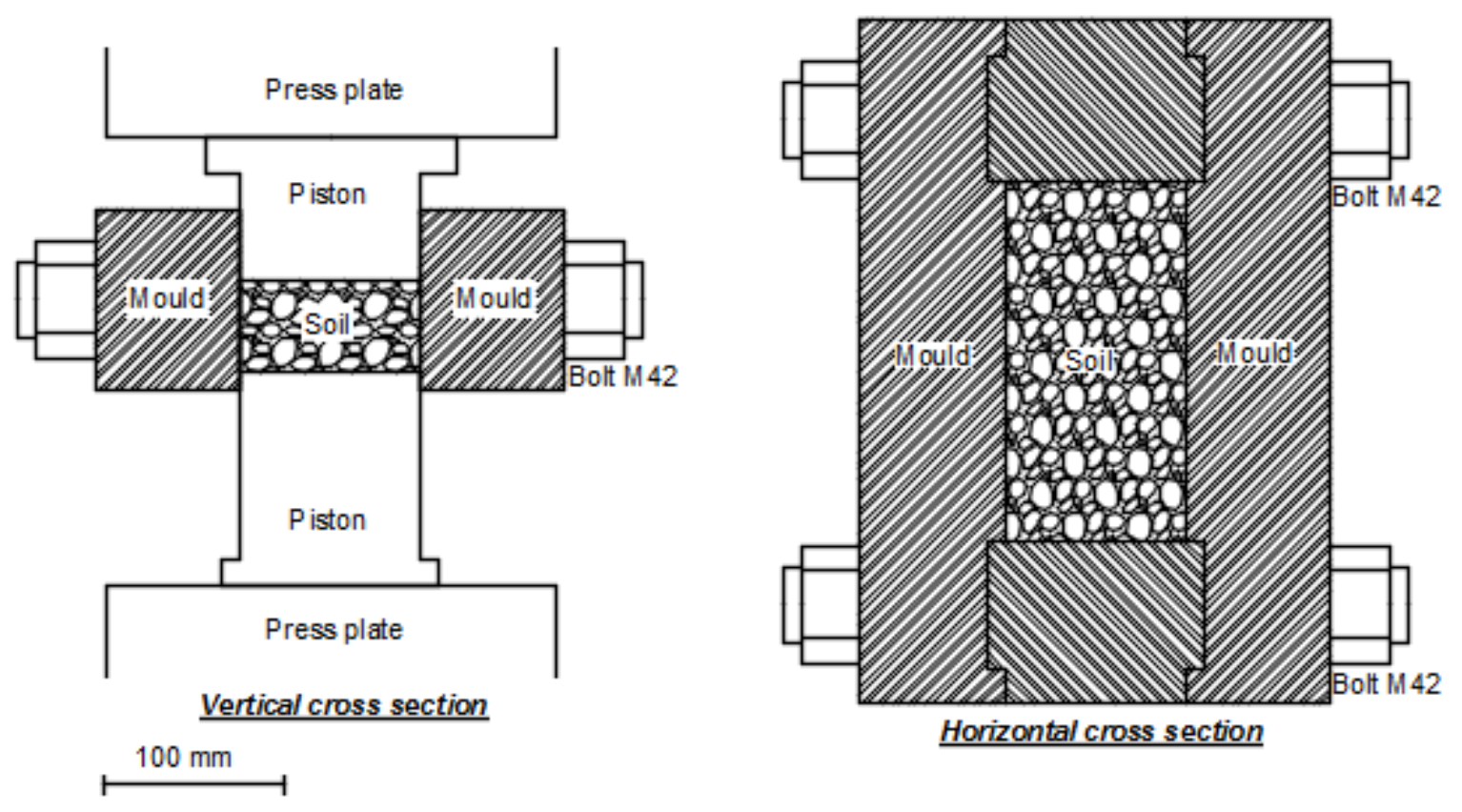

Figure 4. Schematic of compaction set-up for earth bricks

After compaction, earth bricks were equalised at room temperature (about $25^{\circ} \mathrm{C}$ ) for a period of two weeks before compression tests were performed. At the end of equalisation, the earth bricks attained an average dry density of $2325 \mathrm{~kg} / \mathrm{m}^{3}$ which is higher than that of cylindrical samples. This is owed to the higher volume to lateral surface ratio of the bricks compared to cylindrical samples, which reduces the effect of lateral friction during compaction. 


\section{RESULTS}

\section{Mechanical properties of cylindrical samples}

\section{Effect of relative humidity}

Previous research by e.g. Dierks and Ziegert (2002), Beckett and Augarde (2012) and Bui et al. (2014) has shown that compressed raw earth exhibits different mechanical characteristics depending on the hygrothermal conditions to which is subjected.

In this work, this aspect was further explored with reference to hypercompacted raw earth by testing five sets of three cylindrical samples compacted to the three pressure levels of 25, 50 and $100 \mathrm{MPa}$, respectively, at the corresponding optimum water contents. After compaction, each set of samples was equalised at different relative humidities of $95 \%, 77 \%, 62 \%, 44 \%$ and $25 \%$ under a constant temperature of $25{ }^{\circ} \mathrm{C}$. Table 2 summarises the main properties of the samples after equalisation at these five humidity levels.

Inspection of Table 2 indicates that, for each humidity level, the three samples show similar water contents regardless of the compaction pressure. Water content reduces as the level of humidity decreases, which in turn produces desaturation and shrinkage with a consequent increase of dry density.

After equalisation, samples were subjected to five cycles of loading-unloading at a constant rate of about $5 \mathrm{kPa} / \mathrm{s}$ to determine the Young modulus. In each cycle, the material behaviour was assumed to be elasto-plastic during loading but prevalently elastic during unloading. Based on this assumption, the Young modulus was calculated as the average slope of the fitting lines of the five unloading curves in the stress-strain plane. After the five cycles, samples were further loaded to 
failure with a constant displacement rate of $0.001 \mathrm{~mm} / \mathrm{s}$ to measure the entire stress-strain curve including the post-peak region.

Both stiffness and strength were related to the total suction, $\psi$ inside the sample, which was calculated from the imposed values of temperature, $T$ and relative humidity, $R H$ (Table 2 ) by means of Kelvin equation:

$$
\psi=-\frac{R T}{V_{m}} \ln (R H)
$$

where $R$ is the universal gas constant and $V_{m}$ is the molar volume of water.

Table 2. Properties of cylindrical samples after equalisation at different humidity levels

\begin{tabular}{|c|c|c|c|c|c|c|c|}
\hline $\begin{array}{l}\text { Relative } \\
\text { humidity }\end{array}$ & $\begin{array}{c}\Psi \\
(\mathrm{MPa})\end{array}$ & $\begin{array}{l}\text { Compaction } \\
\text { pressure }\end{array}$ & $\begin{array}{c}w \\
(\%)\end{array}$ & $\begin{array}{c}\rho_{b} \\
\left(\mathrm{~kg} / \mathrm{m}^{3}\right)\end{array}$ & $\begin{array}{c}\rho_{d} \\
\left(\mathrm{~kg} / \mathrm{m}^{3}\right)\end{array}$ & $\begin{array}{c}n \\
(-)\end{array}$ & $\begin{array}{c}S_{r} \\
(\%)\end{array}$ \\
\hline \multirow{3}{*}{$95 \%$} & \multirow{3}{*}{7} & $25 \mathrm{MPa}$ & 4.1 & 2208 & 2121 & 0.204 & 42.7 \\
\hline & & $50 \mathrm{MPa}$ & 4.2 & 2235 & 2145 & 0.195 & 46.2 \\
\hline & & $100 \mathrm{MPa}$ & 4.1 & 2334 & 2242 & 0.158 & 58.0 \\
\hline \multirow{3}{*}{$77 \%$} & \multirow{3}{*}{36} & $25 \mathrm{MPa}$ & 3.9 & 2212 & 2129 & 0.201 & 41.3 \\
\hline & & $50 \mathrm{MPa}$ & 4.0 & 2246 & 2160 & 0.189 & 45.6 \\
\hline & & $100 \mathrm{MPa}$ & 3.7 & 2333 & 2250 & 0.155 & 53.5 \\
\hline \multirow{3}{*}{$62 \%$} & \multirow{3}{*}{66} & $25 \mathrm{MPa}$ & 3.4 & 2213 & 2140 & 0.197 & 37.0 \\
\hline & & $50 \mathrm{MPa}$ & 3.3 & 2243 & 2171 & 0.185 & 38.7 \\
\hline & & $100 \mathrm{MPa}$ & 3.0 & 2351 & 2283 & 0.143 & 47.8 \\
\hline \multirow{3}{*}{$44 \%$} & \multirow{3}{*}{112} & $25 \mathrm{MPa}$ & 2.6 & 2202 & 2146 & 0.194 & 28.7 \\
\hline & & $50 \mathrm{MPa}$ & 2.6 & 2243 & 2186 & 0.179 & 31.7 \\
\hline & & $100 \mathrm{MPa}$ & 2.5 & 2360 & 2302 & 0.136 & 42.4 \\
\hline \multirow{3}{*}{$25 \%$} & \multirow{3}{*}{190} & $25 \mathrm{MPa}$ & 2.2 & 2195 & 2148 & 0.194 & 24.4 \\
\hline & & $50 \mathrm{MPa}$ & 2.1 & 2242 & 2196 & 0.176 & 26.2 \\
\hline & & $100 \mathrm{MPa}$ & 2.0 & 2355 & 2309 & 0.133 & 34.6 \\
\hline & & $\begin{array}{l}\text { tal suction } \\
\text { lry density }\end{array}$ & wate & $\begin{array}{l}\text { tent; } \rho \\
r, \text { degr }\end{array}$ & $\begin{array}{l}\text { k densit } \\
\text { aturatic }\end{array}$ & & \\
\hline
\end{tabular}

Figure 5 shows the variation of Young modulus with total suction for the samples compacted at all three pressures. In general, stiffness increases as suction grows from $7 \mathrm{MPa}$ to $112 \mathrm{MPa}$ but then tends to a constant value as suction increases beyond $112 \mathrm{MPa}$. For the samples compacted at 25 
and $50 \mathrm{MPa}$, the value of stiffness increases by a factor of about 2.5 as suction grows from the lowest value of $7 \mathrm{MPa}$ to the highest value of $190 \mathrm{MPa}$. Instead, for the samples compacted at 100 $\mathrm{MPa}$, the stiffness increases by a factor of about 3.1 over the same suction range. Similar to Young modulus, Figure 6 shows that the peak value of compressive strength increases as suction grows from $7 \mathrm{MPa}$ to $112 \mathrm{MPa}$ but then tends to stabilise as suction increases further.

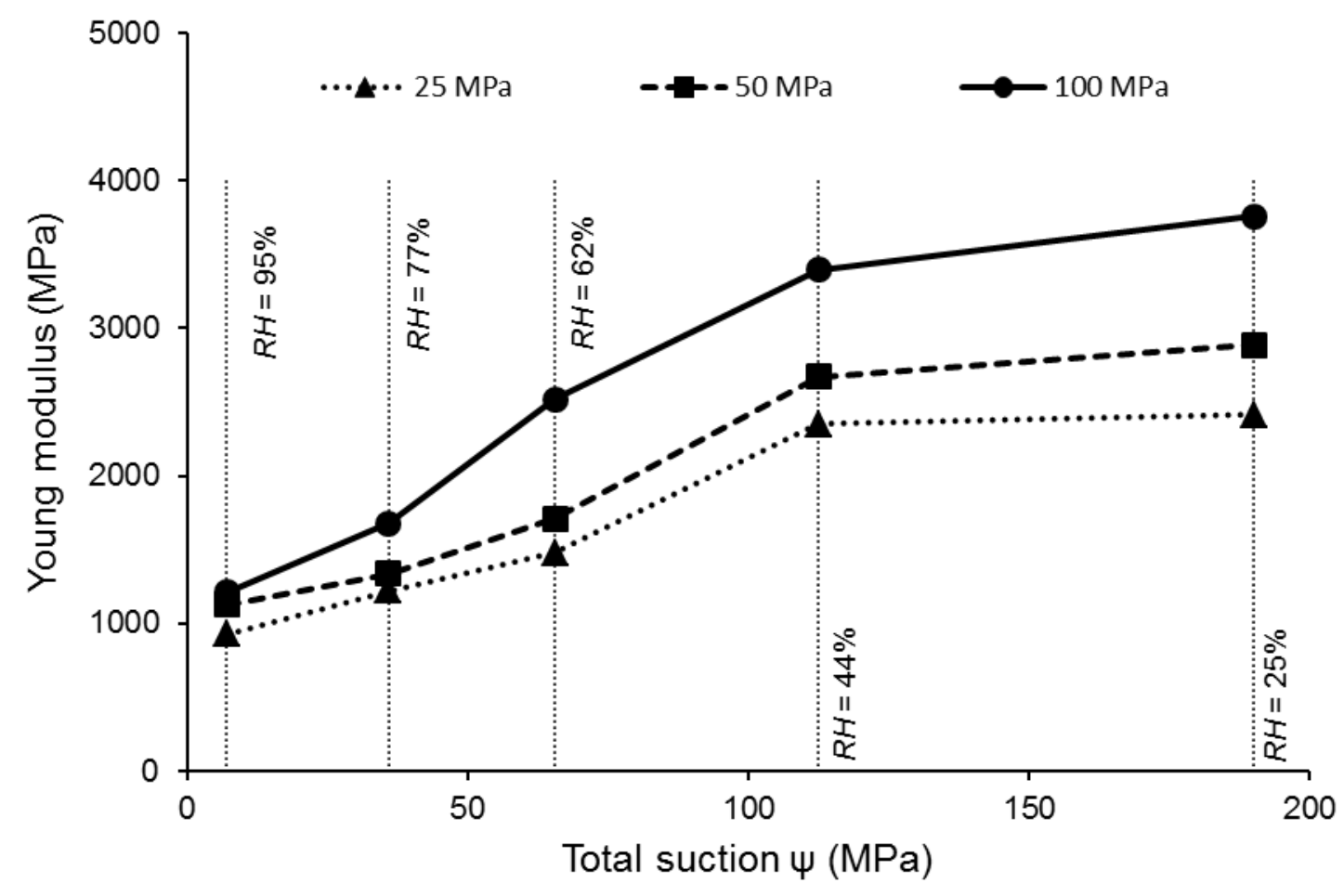

Figure 5. Variation of Young modulus with total suction 


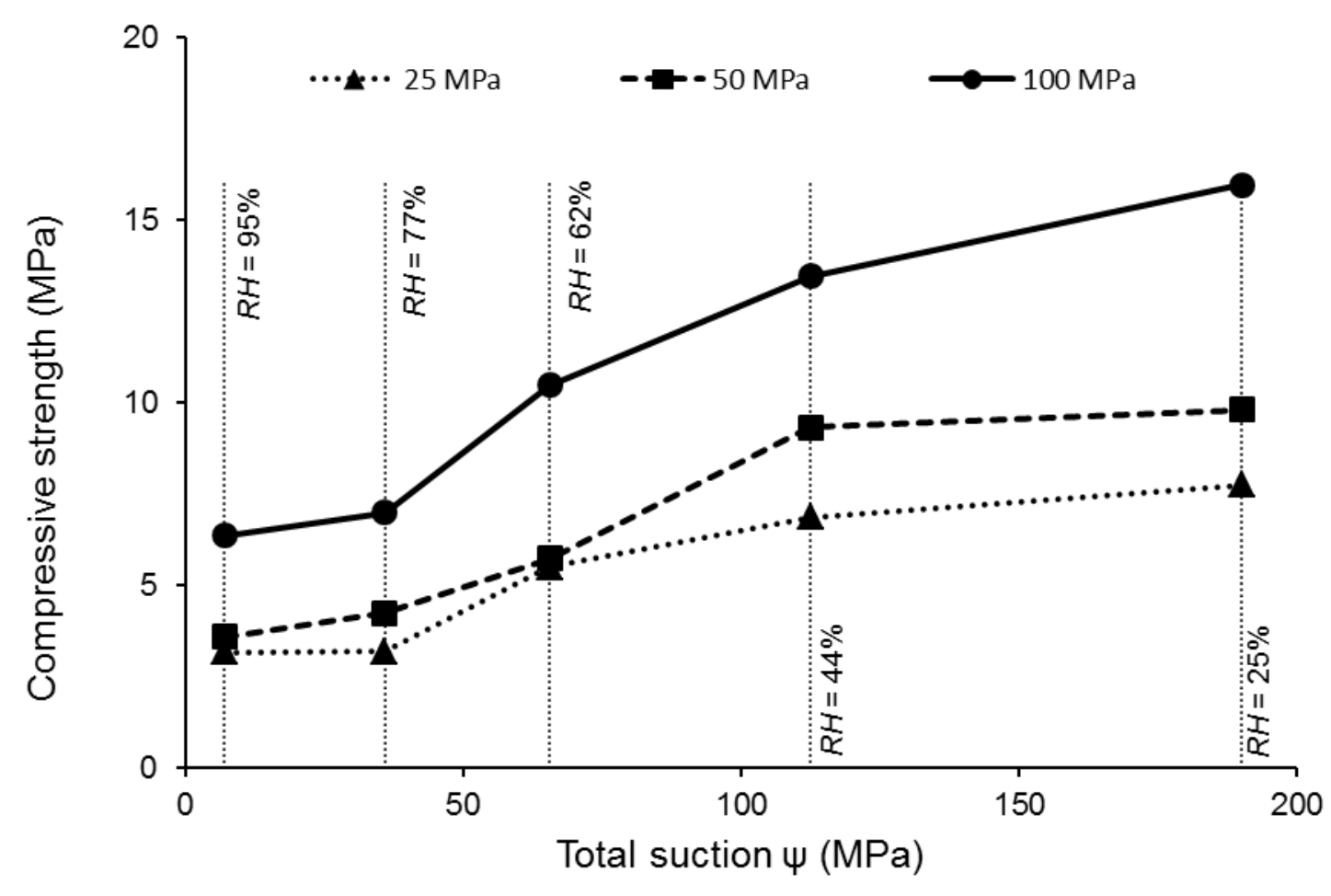

Figure 6. Variation of peak compressive strength with total suction

The progressively smaller increases of both Young modulus and compressive strength with growing suction are in agreement with the simple meniscus model of Fisher (1926). This model shows that the "bonding" effect produced by a water meniscus at the contact between two identical spheres grows with suction towards a constant asymptote.

\section{Effect of consolidation time}

As previously discussed, the hypercompaction procedure includes a constant-load consolidation phase that lasts until the displacement rate becomes smaller than $0.01 \mu \mathrm{m} / \mathrm{s}$. This is a very strict requirement which implies fabrication times longer than two hours for a single brick and might therefore hinder industrial exploitation of the proposed manufacturing method. Further investigation has therefore been undertaken with a view of possibly relaxing the above consolidation criterion.

Cylindrical samples were compacted at the pressure of $100 \mathrm{MPa}$ and at the corresponding optimum water content of $5.2 \%$ with different consolidation times of $0.5,1,2,5,10,20,40,80$ and 160 
minutes. After consolidation, all samples were equalised at a temperature of $25{ }^{\circ} \mathrm{C}$ and a relative humidity of $62 \%$ for two weeks prior to being subjected to unconfined compression.

Figure 7 shows that the post-equalisation dry density of the samples does not increase significantly as the consolidation time becomes longer than 20 minutes. This is consistent with the fact that the largest share of compression occurs during primary consolidation which lasts only few minutes (see Figure 2). In the same way, Figure 8 shows that both Young modulus and peak compressive strength grow as the consolidation time increases up to 20 minutes but then become approximately constant as the consolidation time increases further.

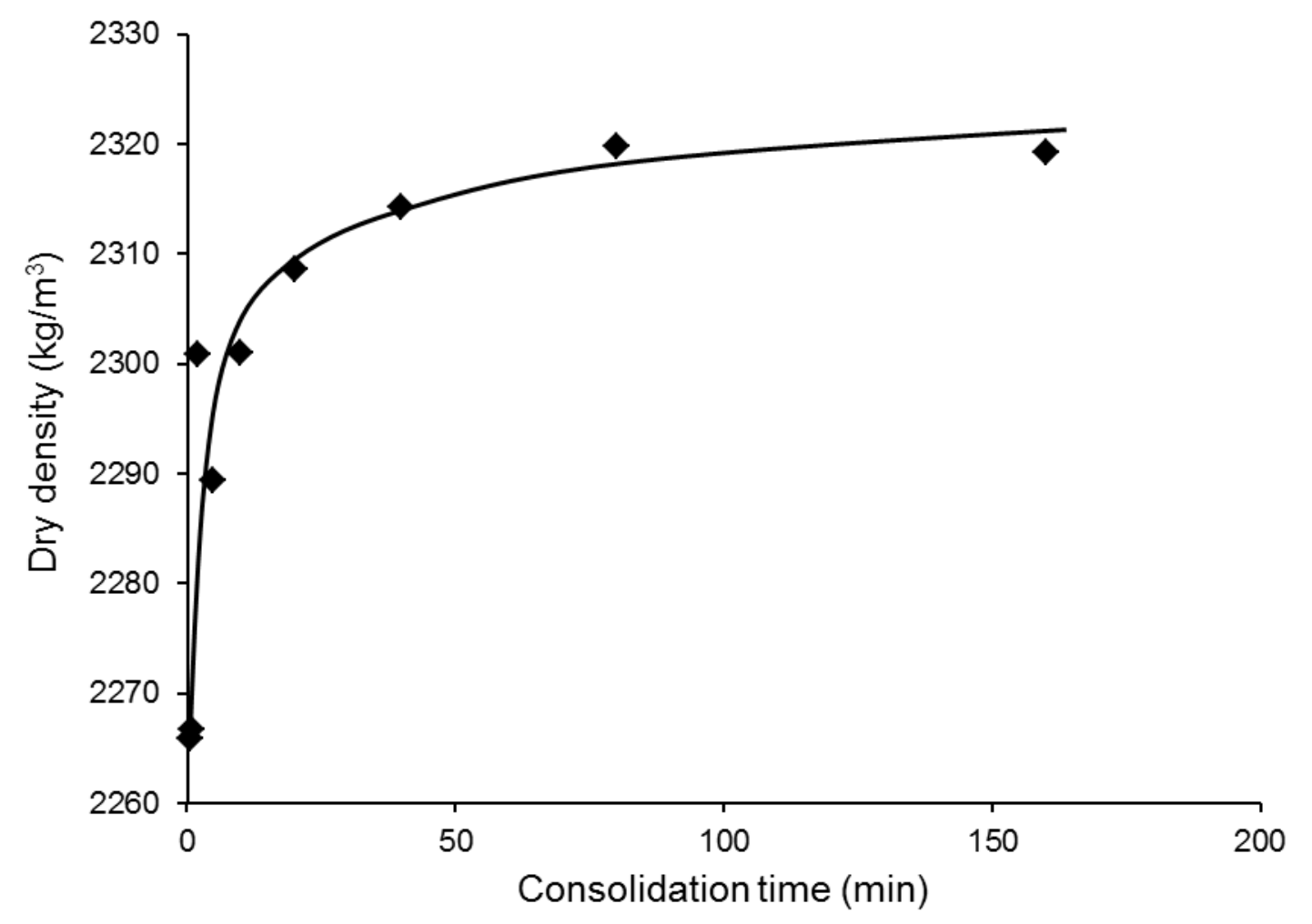

Figure 7. Variation of dry density with consolidation time 


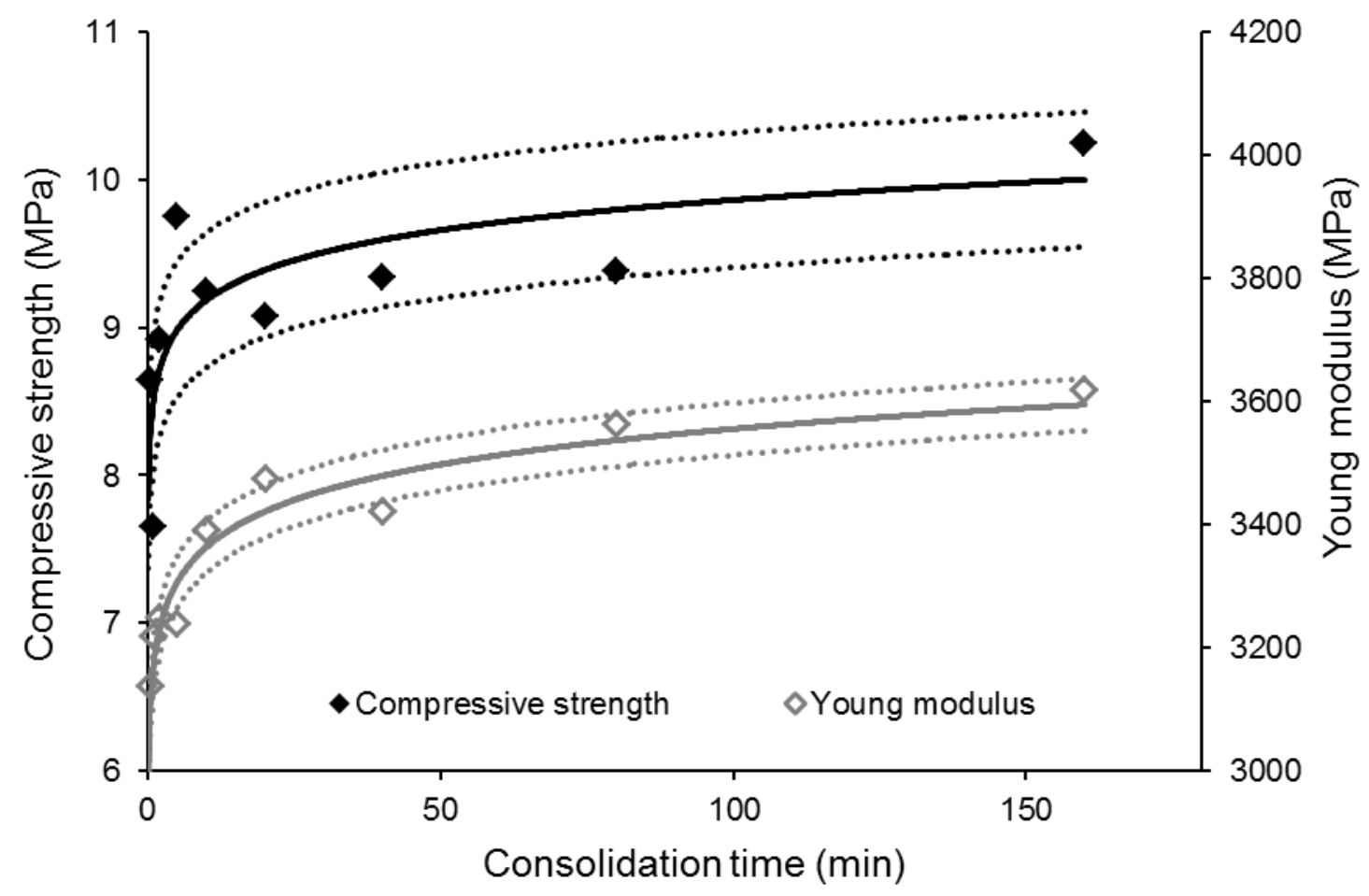

Figure 8. Variation of Young modulus and compressive strength with consolidation time

The very long original consolidation time of more than two hours could therefore be reduced by a factor of six without significantly affecting material properties. At the same time, a very short consolidation time of only few seconds (as it often happens in current construction practice) is not enough to ensure the highest values of stiffness and strength.

\section{Mechanical properties of bricks}

This section investigates the compressive strength of hypercompacted bricks tested under: a) different orientations to study the effect of slenderness ratio and b) different levels of end-friction to study the effect of spurious confinement of the loaded faces. A similar study was also performed by Aubert et al. (2016), who focused however on extruded rather than compacted bricks.

The effect of compaction-induced anisotropy was next investigated by loading dry-sawn cubic specimens along the three perpendicular directions. Finally, a series of tests was performed on superposed half-bricks, with or without a mortar joint, to analyse the effect of interfaces on the compressive strength of masonry structures. 
All tests presented in this section were run at a constant load rate of $80 \mathrm{kPa} / \mathrm{s}$, which is also similar to the load rate employed by Aubert et al. (2016). The tests on entire bricks were performed by using a 3R RP $3000 \mathrm{TC} / \mathrm{TH}$ press, which is a more powerful press than that used for the previous tests on cylindrical samples. This was necessary because a bigger force is needed to fail a large brick compared to a small cylindrical specimen.

\section{Effect of slenderness ratio}

The effect of slenderness ratio (i.e. the ratio between the dimension parallel to the loading direction and the smallest dimension of the perpendicular cross section) on the measured strength was investigated by varying the orientation of the brick inside the press. Bricks were loaded along directions 1, 2 and 3, which are the directions perpendicular to the largest, intermediate and smallest faces of the brick and correspond to slenderness ratios of 0.5, 2 and 4, respectively.

Figure 9 shows the variation of the peak compressive strength with sample slenderness ratio together with a schematic of the three perpendicular loading directions. Each histogram bar represents the average compressive strength measured on six bricks while the thin vertical lines indicate the standard deviation. The highest compressive strength is measured when the load is applied on the largest surface of the brick corresponding to a slenderness ratio of 0.5 . This is a consequence of the friction between the large brick faces and the press plates, which strongly confines the sample producing a fictitious increase of strength. A similar result was obtained by Aubert et al. (2013) who measured a compressive strength higher than $45 \mathrm{MPa}$ for an earth brick tested in analogous conditions. They also recognised that this extremely high value of compressive strength is an anomaly owed to the low slenderness ratio of the tested brick.

More realistic values of compressive strength were measured when the load was applied along the other two directions, i.e. directions 2 and 3, corresponding to slenderness ratios of 2 and 4, respectively. Compressive strength was similar along both these directions, with a slightly lower 
value when the load was applied on the intermediate brick face. This small difference might be attributable to the distinct failure mechanisms observed in these two cases. A shearing failure mechanism with an inclined failure surface was observed when the load was applied along direction 2, corresponding to a slenderness ratio of 2. Conversely, a sub-vertical failure surface, typical of a compressive failure mechanism, was observed when the load was applied along direction 3, corresponding to a slenderness ratio of 4 .

The one-dimensional compaction process during fabrication of the earth bricks is likely to generate an anisotropic fabric, which may influence the values of strength measured in different directions. Therefore, part of the differences observed between the above three loading configurations might be due to the anisotropy of the material. This aspect will be discussed later in the paper.

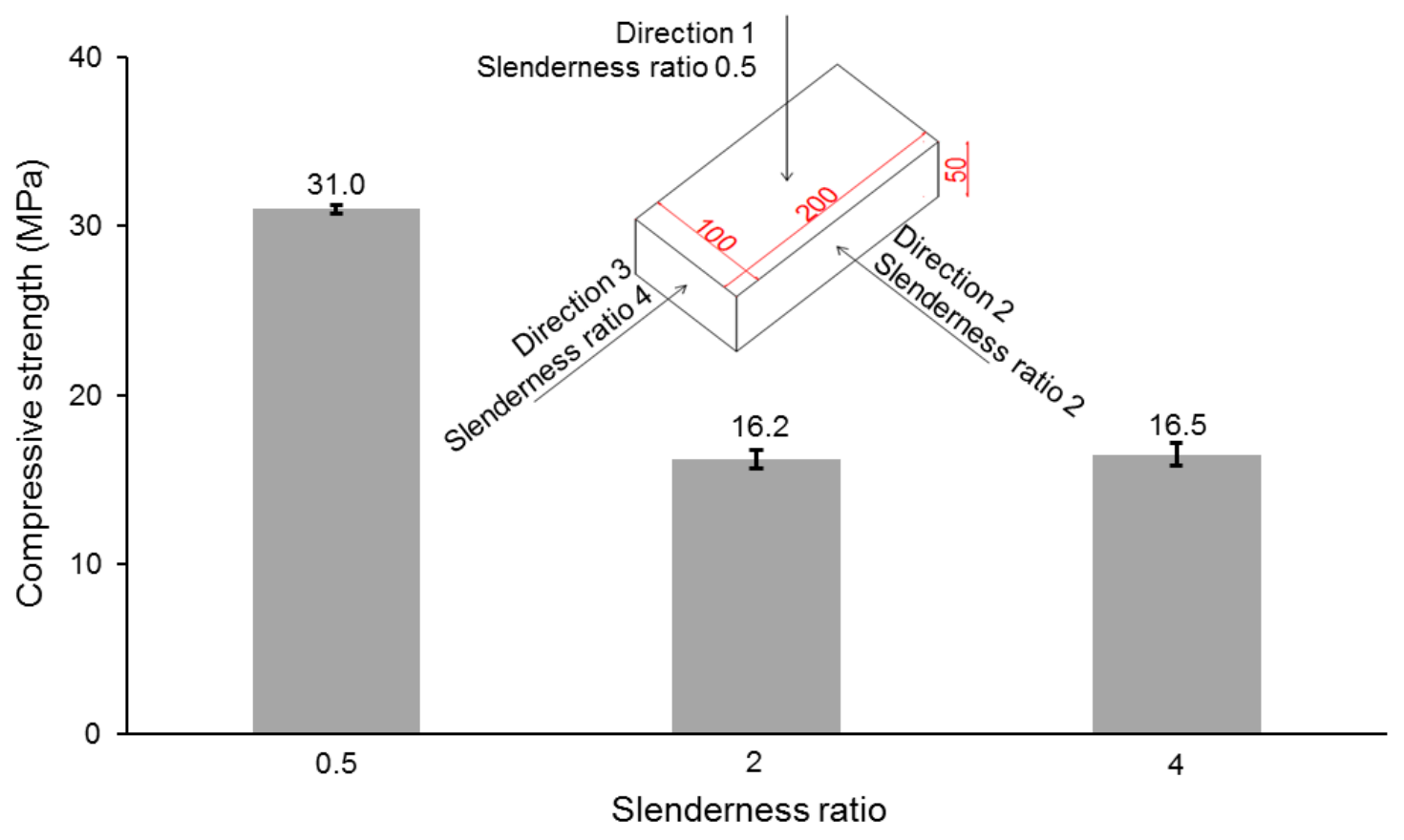

Figure 9. Compressive strength for different brick slenderness ratios 


\section{Effect of end friction confinement}

During loading, the friction between the brick extremities and the press plates confines the sample, which increases the measured value of compressive strength. To quantify this spurious effect, an additional set of six bricks was tested with top and bottom surfaces capped with Teflon sheets to reduce friction, as suggested by Ciancio and Gibbings (2012). All six bricks were loaded on the smallest face, i.e. along direction 3, corresponding to the biggest slenderness ratio of 4 .

Figure 10 shows that the average values of brick strength with and without Teflon capping are very similar, with a slightly lower value for the capped bricks. The tests on capped bricks also exhibit a smaller dispersion of results as indicated by the lower value of standard deviation.

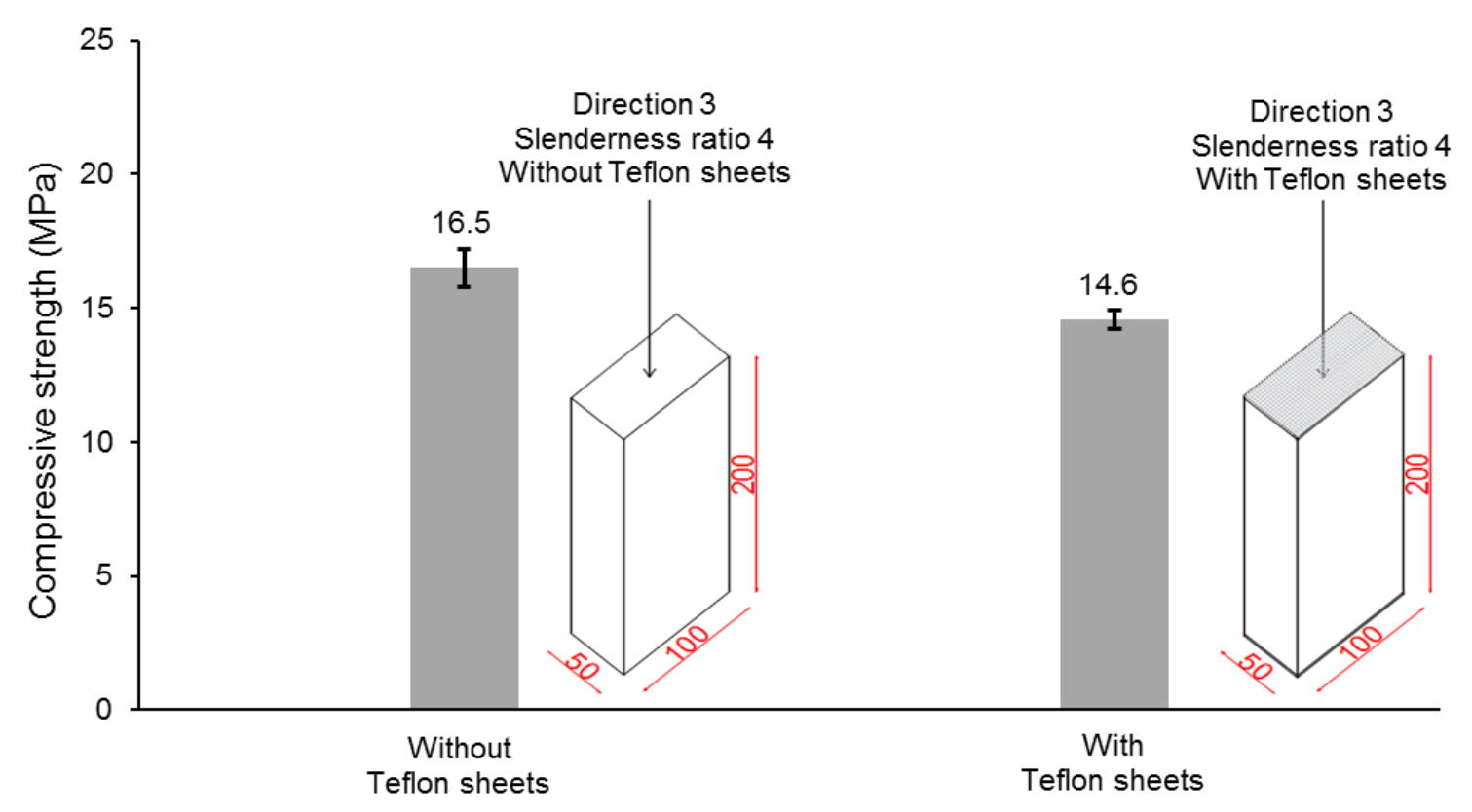

Figure 10. Compressive strength with and without friction confinement 
The effect of sample confinement reduces as the end-friction decreases and the slenderness ratio increases, which means that the most realistic estimate of material strength is provided by the Teflon capped samples of Figure 10.

Table 3 demonstrates that the hypercompaction process largely improves the mechanical properties of earth bricks, whose strength becomes similar to that of traditional materials such as stabilised compacted earth and standard masonry bricks. The strength of hypercompacted bricks is also compliant with the requirements for standard masonry construction according to the norm ASTM C270 (2014).

Note that, for the raw earth material tested by Guettala (1997), compressive strength varies from 5.2 $\mathrm{MPa}(0 \%$ of cement, i.e. unstabilized soil) to $12.9 \mathrm{MPa}$ (10\% of cement). In the latter case, the percentage of cement is so high that the "green" prerogatives of the earthen material are almost entirely compromised (Bui et al., 2014). Conversely, the hypercompacted bricks described in this work attain values of compressive strength as high as $14.6 \mathrm{MPa}$ while retaining the environmental advantages of unstabilized earth construction.

Table 3. Comparison in terms of compressive strength

\begin{tabular}{c|c}
\hline Material & Compressive strength (MPa) \\
\hline Hypercompacted earth bricks (present work) & 14.6 \\
\hline Stabilised compacted earth (Guettala, 1997) & From 5.2 to 12.9 \\
\hline Standard masonry bricks (ASTM C270, 2014) & From 6.9 to 27.6 \\
\hline
\end{tabular}

Note that the comparison presented in Table 3 is limited to values of compressive strength measured under typical ambient conditions. Similar conclusions cannot be drawn for wet ambient conditions because of the bigger moisture sensitivity of unstabilised earth compared to stabilised earth or standard masonry brick (see, for example, Kariyawasam and Jayasinghe (2016)). 


\section{Effect of anisotropy}

One-dimensional compaction generates an anisotropic fabric which induces a dependency of mechanical behaviour on the direction of loading. To investigate this aspect, a number of additional tests were performed on specimens loaded along different directions. All specimens used in this series of tests had a cubic shape to eliminate the effect of slenderness ratio.

Three sets of six specimens with dimensions $50 \times 50 \times 50 \mathrm{~mm}^{3}$ were dry-sawn with an electric circular saw from three different bricks. The first set of specimens was loaded along the direction 1 perpendicular to the largest face of the brick (i.e. parallel to the direction of compaction). The other two sets were instead loaded along the directions 2 and 3 perpendicular to the intermediate and smallest faces of the brick, respectively (i.e. perpendicular to the direction of compaction). All specimens were loaded without Teflon capping.

Figure 11 shows the average values of peak compressive strength measured for each set of specimens together with a schematic of the three perpendicular loading directions. Inspection of Figure 11 confirms the effect of anisotropy on mechanical behaviour and shows that the specimens loaded parallel to the direction of compaction exhibit a level of strength that is about $10 \%$ higher than that measured along the other two directions. For comparison, Aubert et al. (2016) found that the strength measured along the direction perpendicular to the extrusion plane was $20 \%$ to $50 \%$ higher than that measured on the direction parallel to the extrusion plane. This suggests that the level of material anisotropy induced by hypercompaction is less significant than that induced by extrusion.

The strength measured on dry-sawn specimens is lower than that measured on intact bricks for all values of aspect ratio (Figure 9). This can be possibly explained by the formation of micro-cracks during the process of dry-sawing, which damages the initially intact material thus deteriorating its mechanical characteristics. 


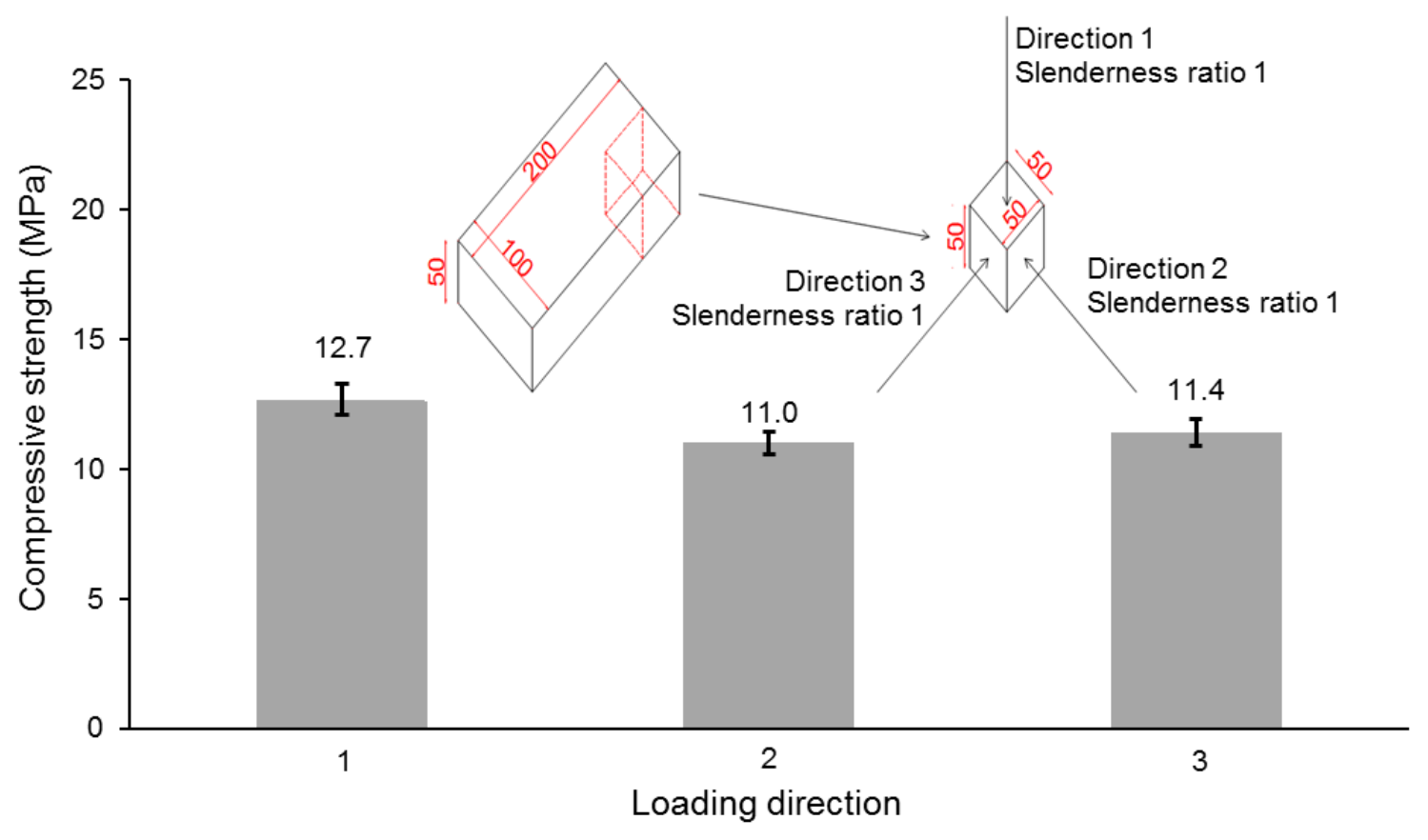

Figure 11. Effect of material anisotropy on compressive strength

\section{Effect of mortar joint}

A common experimental procedure for estimating the compressive strength of a masonry assembly consists in loading two superposed half-bricks separated by a mortar layer (RILEM Technical Committee 164, 1994).

In the present work, we tested two sets of six cubic samples made of superposed dry-sawn halfbricks. The test consisted in the application of a compressive load perpendicular to the interface between the half-bricks and parallel to the direction of compaction. In the first set of samples, the two halves were simply superposed without any mortar, whereas, in the second set, the two halves were stuck together by means of a cement mortar prepared according to the norm NF EN 196-1 (AFNOR, 2006). The mortar-joined samples were tested after a curing period of 28 days at a constant temperature of $25{ }^{\circ} \mathrm{C}$. Figure 12 shows that the average compressive strength of the mortar-joined samples is considerably smaller than that of the samples without any mortar. This is probably due to the relatively high water content of the mortar layer, which wets the brick surface thus damaging the unstabilized earth. The weaker bond between bricks is also likely to result in a 
lower flexural strength of the masonry assembly at the wall scale. In practical applications, it might therefore be necessary to use a soil mortar of similar composition to the earth bricks or a cement mortar with a lower water content than that prescribed by the norm NF EN 196-1 (AFNOR, 2006).

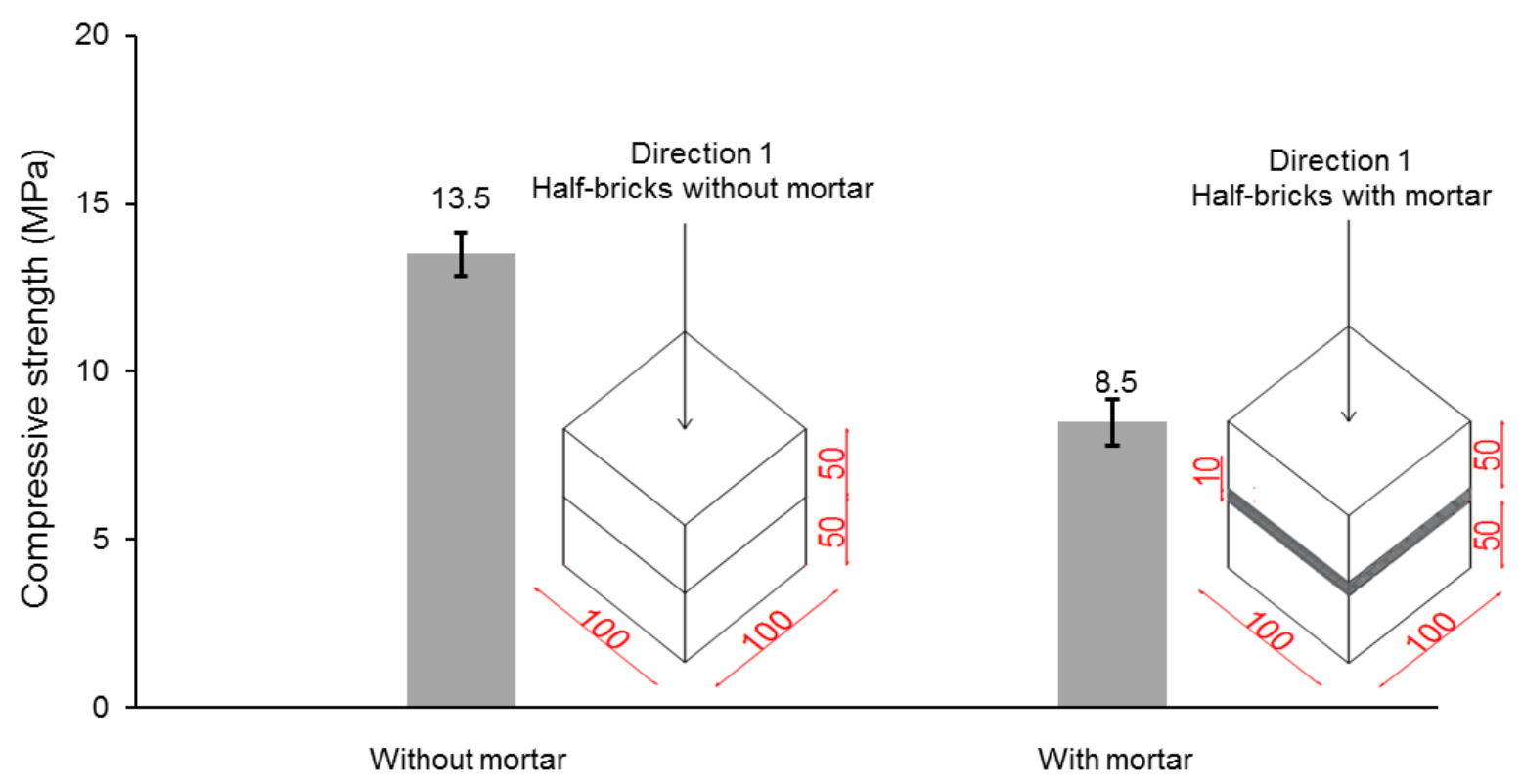

Figure 12. Compressive strength of brick assemblies with or without cement mortar joints

\section{CONCLUSIONS}

The present paper proposes a new hypercompaction procedure to manufacture a raw earth material with excellent mechanical properties for the construction of masonry buildings. The manufacturing procedure, which consists in the application of a very high compaction pressure, up to $100 \mathrm{MPa}$, to a moist earth, has been employed in this work to fabricate small cylindrical samples and full scale masonry bricks. The hypercompacted earth exhibits very high values of compressive strength, which are comparable with those of traditional building materials such as stabilised compacted earth and fired bricks.

The main outcomes of the present research can be summarised as follows: 
- Effect of relative humidity. The stiffness and strength of hypercompacted earth increase as ambient humidity decreases from $95 \%$ to $44 \%$ (which correspond to an increase of total suction inside the material from $7 \mathrm{MPa}$ to $112 \mathrm{MPa}$ ) but tend subsequently to level off as relative humidity decreases further.

- Effect of consolidation time. The stiffness and strength of the hypercompacted earth tend to grow as the constant-load consolidation time during fabrication is increased up to 20 minutes. For longer consolidation times, stiffness and strength remain virtually unchanged. This suggests that, while a very long consolidation time is generally unnecessary, a quick compaction of only few seconds (as it often happens in current construction practice) cannot ensure the best mechanical properties.

- Effect of slenderness ratio. Unrealistically high values of compressive strength are measured when the load is applied on the biggest brick face (i.e. slenderness ratio of 0.5 ) due to the large confinement caused by the friction against the press plates. Lower but more realistic values of compressive strength are instead measured when the load is applied on the intermediate and smallest brick faces (i.e. slenderness ratios of 2 and 4 , respectively).

- Effect of end friction confinement. The most representative value of material strength is measured from bricks tested with the highest slenderness ratio (i.e. loaded on the smallest face) and capped with Teflon sheets. This configuration minimizes the confining effect of the friction between the brick extremities and press plates.

- Effect of anisotropy. The process of one-dimensional compaction induces an anisotropic material fabric, which results in higher values of compressive strength if the material is loaded along the direction of compaction.

- Effect of mortar joint. The presence of cement mortar joints between bricks induces a significant reduction of compressive strength. This is probably due to the high water content of the cement mortar that wets the surface of the bricks thus damaging the material. 


\section{Compliance with Ethical Standards:}

Funding: This study was funded by the "Conseil régional d'Aquitaine" and the "Agglomération

Côte Basque Adour" through the project MECAD "Matériaux Eco-renforcés pour la Construction et l'Aménagement Durable" (dossier n. 20131101001). The authors declare that they have no conflict of interest.

\section{REFERENCES}

AFNOR (1991). NF P 94-054; Soils: investigation and testing - Determination of particle densityPycnometer method.

AFNOR (1992). NF P 94-057. Soils: investigation and testing - Granulometric analysis Hydrometer method.

AFNOR (1993). NF P 94-051; Soils: Investigation and testing - Determination of Atterberg's limits - Liquid limit test using Casagrande apparatus - Plastic limit test on rolled thread.

AFNOR (1995). XP P 94-041. Soils: investigation and testing - Granulometric description - Wet sieving method.

AFNOR (2006). NF EN 196-1. Methods of testing cement - Part 1 : determination of strength.

ASTM C270 (2014). Standard Specification for Mortar for Unit Masonry. American Society for Testing and Materials International.

Allinson, D., \& Hall, M. (2010). Hygrothermal analysis of a stabilised rammed earth test building in the UK. Energy and Buildings, 42(6), 845-852.

Attom, M. F. (1997). The effect of compactive energy level on some soil properties. Applied Clay Science, 12(1), 61-72.

Aubert, J. E., Fabbri, A., Morel, J. C., \& Maillard, P. (2013). An earth block with a compressive strength higher than 45MPa!. Construction and Building Materials, 47, 366-369.

Aubert, J. E., Maillard, P., Morel, J. C., \& Al Rafii, M. (2016). Towards a simple compressive strength test for earth bricks?. Materials and Structures, 49(5), 1641-1654.

Beckett, C. T. S., \& Augarde, C. E. (2012). The effect of humidity and temperature on the compressive strength of rammed earth. In Proceedings of 2 nd European Conference on Unsaturated Soils (pp. 287-292).

Bruno, A.W., Gallipoli, D., Perlot, C., Mendes, J. \& Salmon, N. (2015). Mechanical properties of unstabilized earth compressed at high pressures. In Proceedings 1st International Conference on Bio-based Building Materials. Clermont-Ferrand, France, 21-24 June 2015, e-ISBN PRO99: 9782-35158-154-4. 
Bui, Q. B., \& Morel, J. C. (2009). Assessing the anisotropy of rammed earth. Construction and building Materials, 23(9), 3005-3011.

Champiré, F., Fabbri, A., Morel, J. C., Wong, H., \& McGregor, F. (2016). Impact of relative humidity on the mechanical behavior of compacted earth as a building material. Construction and Building Materials, 110, 70-78.

Ciancio, D., \& Gibbings, J. (2012). Experimental investigation on the compressive strength of cored and molded cement-stabilized rammed earth samples. Construction and Building Materials, 28(1), 294-304.

Dierks, K., \& Ziegert, C. (2002). Neue Untersuchungen zum Materialverhaltenvon Stampflehm. Steingass, P.: Moderner Lehmbau 2002.

Fisher, R. A. (1926). On the capillary forces in an ideal soil; correction of formulae given by WB Haines. The Journal of Agricultural Science, 16(03), 492-505.

Guettala, A., \& Guenfoud, M. (1997). Béton de terre stabilisé: Propriétés physico-mécaniques et influence des types d'argiles. La technique moderne,89(1-2), 21-26.

Kariyawasam, K. K. G. K. D., \& Jayasinghe, C. (2016). Cement stabilized rammed earth as a sustainable construction material. Construction and Building Materials, 105, 519-527.

Kouakou, C. H., \& Morel, J. C. (2009). Strength and elasto-plastic properties of non-industrial building materials manufactured with clay as a natural binder. Applied Clay Science, 44(1), 27-34.

McGregor, F., Heath, A., Fodde, E., \& Shea, A. (2014). Conditions affecting the moisture buffering measurement performed on compressed earth blocks. Building and Environment, 75, 11-18.

Mesbah, A., Morel, J. C., \& Olivier, M. (1999). Clayey soil behaviour under static compaction test. Materials and structures, 32(223), 687-694.

Morel, J. C., Mesbah, A., Oggero, M., \& Walker, P. (2001). Building houses with local materials: means to drastically reduce the environmental impact of construction. Building and Environment, 36(10), 1119-1126.

Olivier, M., \& Mesbah, A. (1986). Le matériau terre: Essai de compactage statique pour la fabrication de briques de terre compressées. Bull. Liaison Lab. Ponts et Chaussées, 146, 37-43.

Pacheco-Torgal, F., \& Jalali, S. (2012). Earth construction: Lessons from the past for future ecoefficient construction. Construction and building materials,29, 512-519.

RILEM Technical Committee 164 (1994). Recommendations for the Testing and Use of Constructions Materials

Skempton, A. W. (1953). The colloidal activity of clays. Selected Papers on Soil Mechanics, 106118.

Taylor, D. W., \& Merchant, W. (1940). A theory of clay consolidation accounting for secondary compression. Journal of Mathematics and Physics, 19(1), 167-185. 
Venkatarama-Reddy, B. V., \& Jagadish, K. S. (1993). The static compaction of soils. Geotechnique, 43(2). 